\title{
Protective Effect of Tincture of Crataegus on Oxidative Stress in Experimental Atherosclerosis in Rats
}

\author{
Raiendran Shanthi, Kamaravelu PARASAKTHY, \\ Putchen Dakshinamurthy DeEPALAKSHMI, \\ and Devaraj Sivasithambaram NIRANJALI* \\ Department of Biochemistry, University of Madras, Guindy \\ Campus, Madras 600 025, India
}

(Received August 19, 1995)

\begin{abstract}
Summary Tincture of Crataegus (TCR) is an antiatherogenic drug consisting of flavonoids, some saponins, and cardioactive amines. It is an alcoholic extract of the berries of the tree Crataegus oxyacantha, commonly called the hawthorn. TCR at a dosage of $0.5 \mathrm{ml} / 100 \mathrm{~g}$ body weight/day for 6 weeks could prevent the increase in lipid peroxidation observed in rats with experimentally induced atherosclerosis. TCR also prevented the decrease in glutathione and $\alpha$-tocopherol content of the liver, aorta, and heart. The decreased activities of some antioxidant enzymes in liver, aorta, and heart tissues were also maintained at normal levels by the drug. TCR also prevented the copper ion-induced oxidation of low-density and very-low-density lipoproteins in vitro. The antiatherogenic effect of TCR appears to be related to its antioxidant property. It is possible that the constituents of TCR act synergistically to ameliorate the oxidative stress during atherogenesis.
\end{abstract}

Key Words: atherosclerosis, lipid peroxidation, tincture of Crataegus, antioxidant enzymes, flavonoids

In the last decade evidence has accumulated that lipid peroxidation plays a crucial role in the pathogenesis of atherosclerosis [1]. Elevated blood lipid concentrations may lead to elevated blood lipid peroxides, contributing to endothelial injury and accelerating the process of atherogenesis [2]. The plasma as well as tissues contains a number of antioxidants that limit lipid peroxidation. Therefore, the antioxidant status should have a major influence on the development of atherosclerosis [3].

We have already confirmed the hypolipidemic [4] and antiatherogenic effect of a herbal drug-tincture of Crataegus (TCR). TCR, an alcoholic extract of the

* To whom correspondence should be addressed. 
ripe berries of hawthorn (Crataegus oxyacantha, L. Rosaceae), has a number of pharmacological properties $[5,6]$. One of the main constituents of TCR is flavonoids apart from triterpene saponins and some cardioactive amines [7]. Flavonoids are polyphenolic antioxidants, but their in vivo effects on atherosclerosis are unknown [8].

The present study was done to clarify if TCR, which is rich in flavonoids, can have a protective effect on lipid peroxidation in experimentally induced athero-

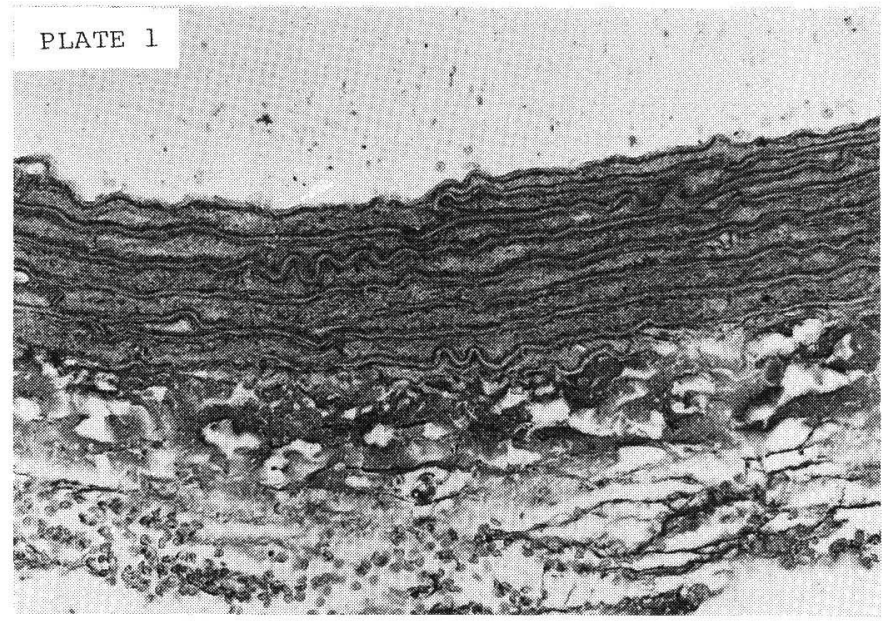

Plate 1. Section of aorta from control rat (group I) showing normal intima and media. Stain: hematoxylin and eosin, magnification: $\times 280$.

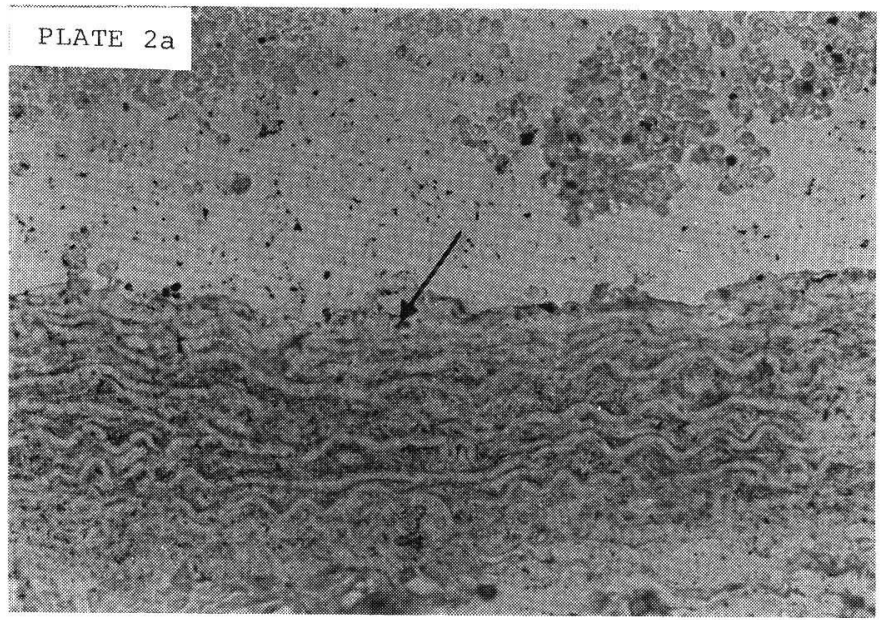

Plate 2 (a). Section of aorta from rat fed atherogenic diet (group II) showing focal subintimal fat accumulation. Stain: hematoxylin and eosin, magnification: $\times 280$.

J. Clin. Biochem. Nutr. 
sclerosis in rats. Since oxidatively modified lipoproteins have been shown to play an important role in atherogenesis, we also tested if TCR can prevent the in vitro oxidation of low-density and very-low-density lipoproteins (LDL and VLDL) induced by copper ions. The results confirmed the in vivo and in vitro antioxidant effect of TCR. Its antiatherogenic property thus appears to be related to its antioxidant effect.

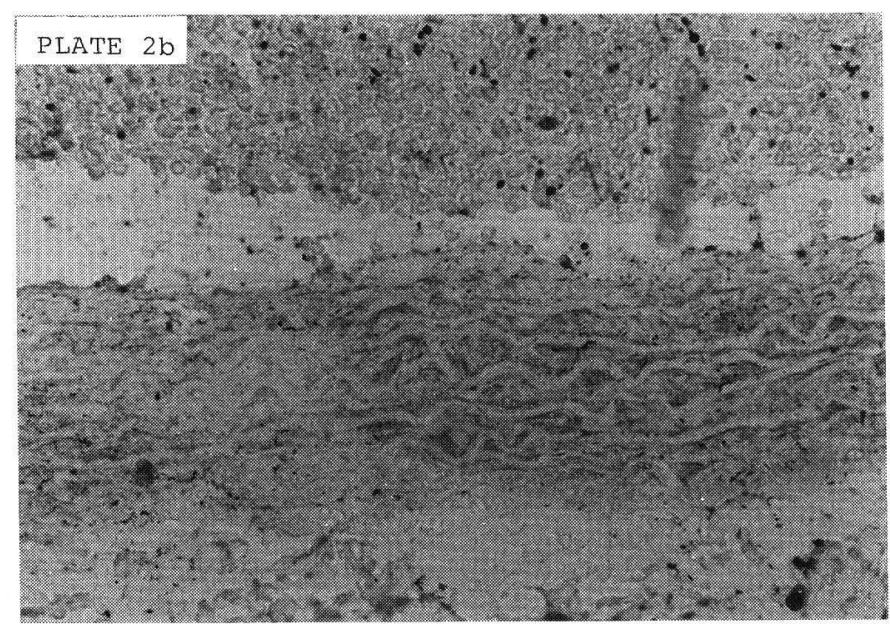

Plate 2 (b). Section of aorta from rat fed atherogenic diet (group II) showing fibrin deposition. Stain: hematoxylin and eosin, magnification: $\times 280$.

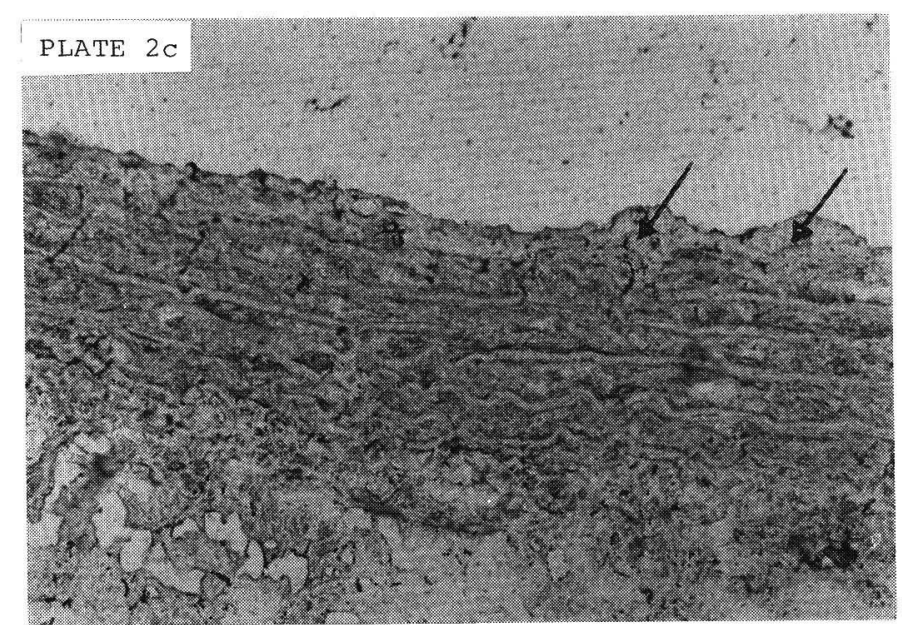

Plate 2 (c). Section of aorta from rat fed atherogenic diet (group II) showing focal collagenization (arrows). Stain: hematoxylin and eosin, magnification: $\times 280$.

Vol. 20, No. 3, 1996 


\section{MATERIALS AND METHODS}

Male Wistar rats weighing $120-150 \mathrm{~g}$ were divided into three groups. Group I (control group) was given normal rat chow (Lipton India, Ltd., Bangalore,

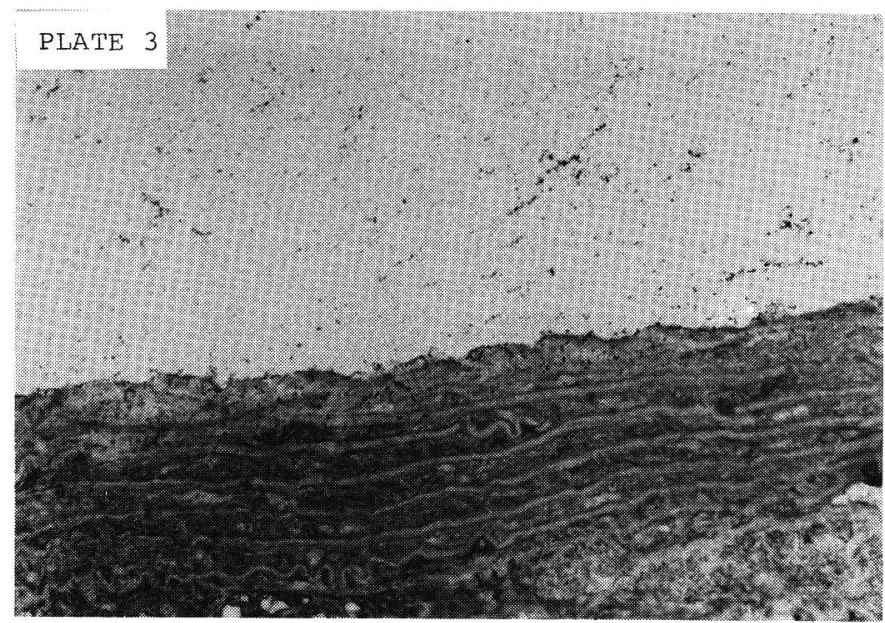

Plate 3. Section of aorta from rat fed atherogenic diet and treated with TCR (group III) showing nearly normal architecture with negligible atherogenic changes. Stain: hematoxylin and eosin, magnification: $\times 280$.

Table 1. Lipid peroxide levels in serum, liver, aorta, and heart of control and experimental animals.

\begin{tabular}{ccccc}
\hline \multirow{2}{*}{ Group } & Serum & \multicolumn{1}{c}{ Liver } & \multicolumn{1}{c}{ Aorta } & Heart \\
\cline { 3 - 5 } & nmol MDA/ml & \multicolumn{3}{c}{ nmol MDA/mg tissue } \\
\hline I & $2.2 \pm 0.2$ & $0.39 \pm 0.04$ & $0.29 \pm 0.02$ & $0.32 \pm 0.03$ \\
II & $3.3 \pm 0.2^{* * *}$ & $0.79 \pm 0.07^{* * *}$ & $0.45 \pm 0.04^{* * *}$ & $0.51 \pm 0.06^{* *}$ \\
III & $2.4 \pm 0.2^{* * *}$ & $0.41 \pm 0.04^{* * *}$ & $0.32 \pm 0.03^{* * *}$ & $0.39 \pm 0.05^{* *}$ \\
\hline
\end{tabular}

Values are expressed as mean \pm SD for 6 animals in each group. Group II was compared with group I; and group III, with group II $\left({ }^{* * *} p<0.001,{ }^{* *} p<0.01\right)$.

Table 2. Concentration of conjugated dienes in serum, liver, aorta, and heart of control and experimental animals.

\begin{tabular}{ccccc}
\hline \multirow{2}{*}{ Group } & Serum & \multicolumn{1}{c}{ Liver } & Aorta & Heart \\
\cline { 3 - 5 } & A.U./ml & \multicolumn{3}{c}{ A.U./g tissue } \\
\cline { 3 - 5 } I & $3.4 \pm 0.1$ & $3.5 \pm 0.5$ & $4.9 \pm 1.0$ & $3.1 \pm 0.3$ \\
II & $4.6 \pm 0.4^{* * *}$ & $7.5 \pm 0.8^{* * *}$ & $9.7 \pm 2.9^{* *}$ & $5.1 \pm 0.6^{* * *}$ \\
III & $3.5 \pm 0.3^{* * *}$ & $4.2 \pm 0.6^{* * *}$ & $5.2 \pm 0.5^{* *}$ & $3.1 \pm 0.7^{* * *}$ \\
\hline
\end{tabular}

Values are expressed as mean $\pm \mathrm{SD}$ for 6 animals in each group. A.U., arbitrary units. Group II was compared with group I; and group III, with group II $\left({ }^{* * *} p<0.001,{ }^{* *} p<\right.$ $0.01)$. 
Table 3. Concentration of reduced glutathione in liver, aorta, and heart of control and experimental animals.

\begin{tabular}{cllc}
\hline Group & \multicolumn{1}{c}{ Liver } & Aorta & Heart \\
\hline I & $6.4 \pm 0.6$ & $5.6 \pm 0.5$ & $4.9 \pm 0.3$ \\
II & $5.1 \pm 0.4^{* *}$ & $2.8 \pm 0.6^{* * *}$ & $3.7 \pm 0.4^{* * *}$ \\
III & $6.7 \pm 0.6^{* * *}$ & $4.7 \pm 0.4^{* * *}$ & $4.5 \pm 0.3^{* * *}$ \\
\hline
\end{tabular}

Values, in $\mu \mathrm{mol} / \mathrm{g}$ tissue, are expressed as mean $\pm \mathrm{SD}$ for 6 animals in each group. Group II was compared with group I; and group III, with group II $\left({ }^{* * *} p<0.001,{ }^{* *} p<0.01\right)$.

Table 4. Concentration of $\alpha$-tocopherol in liver, aorta, and heart of control and experimental animals.

\begin{tabular}{cccc}
\hline Group & Liver & Aorta & Heart \\
\hline I & $7.8 \pm 0.6$ & $2.6 \pm 0.3$ & $6.2 \pm 0.4$ \\
II & $2.7 \pm 0.5^{* * *}$ & $2.0 \pm 0.4^{*}$ & $5.7 \pm 0.3^{*}$ \\
III & $4.8 \pm 0.4^{* * *}$ & $2.8 \pm 0.4^{* *}$ & $6.1 \pm 0.3^{*}$ \\
\hline
\end{tabular}

Values, in $\mu \mathrm{g} / \mathrm{g}$ tissue, are expressed as mean $\pm \mathrm{SD}$ for 6 animals in each group. Group II was compared with group I; and group III, with group II $\left({ }^{* * *} p<0.001,{ }^{* *} p<0.01\right.$, $* p<0.05)$.

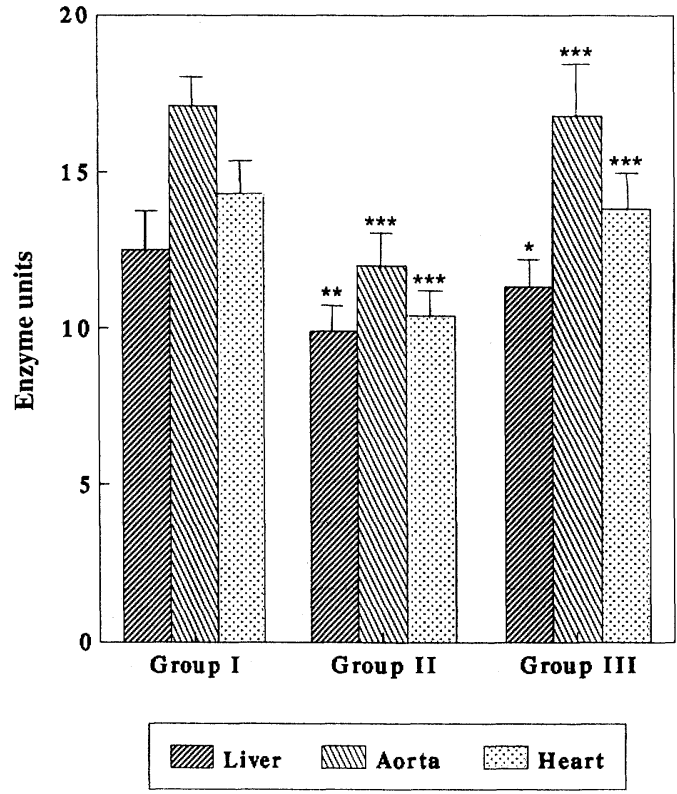

Fig. 1. Activity of superoxide dismutase in liver, aorta, and heart of control and experimental animals. Values in units/mg protein are given as mean \pm SD for 6 animals in each group. One unit is the amount of enzyme that causes 50\% inhibition of adrenaline autooxidation. Group II was compared with group I, and group III, with group II $\left({ }^{* * *} p<0.001,{ }^{* *} p<0.01,{ }^{*} p<0.05\right)$. 
India). Groups II and III were given the atherogenic diet [9] for 6 weeks. The atherogenic diet mainly contained $1.5 \%$ cholesterol, $0.5 \%$ cholic acid, $10 \%$ butter, $59 \%$ sucrose, $24 \%$ casein, $5 \%$ salt mixture, and vitamins as prescribed. An excess of vitamin $\mathrm{D}_{2}$ (1.25 million USP units per $\mathrm{kg}$ diet) was also added. Group III rats were given TCR simultaneously with the atherogenic diet at an oral dosage of 0.5 $\mathrm{ml} / 100 \mathrm{~g}$ body weight/day for 6 weeks. The atherosclerotic changes were studied by histopathological observation of the aortic arches of the control and experimental animals.

At the end of 6 weeks another set of rats from the three groups was killed by cervical dislocation. Blood was collected for the separation of serum. Liver, heart, and aorta were dissected out and washed with ice-cold saline. These tissues were weighed and homogenized in $0.15 \mathrm{M}$ potassium chloride solution. The homogenates were centrifuged at $800 \times g$ for $10 \mathrm{~min}$, and aliquots of the supernatants were used for the estimations of the antioxidant enzymes, lipid peroxides (in terms of malondialdehyde, MDA) [10] and reduced glutathione (GSH) [11]. The antioxidant enzymes assayed in the tissue homogenates were superoxide dismutase (SOD) [12], catalase (CAT) [13], glutathione peroxidase (GPx) [14], and glutathione-Stransferase (GST) [15]. Tissue protein content was also estimated by Lowry's method. Another set of weighed tissues was extracted thoroughly with chloroform-

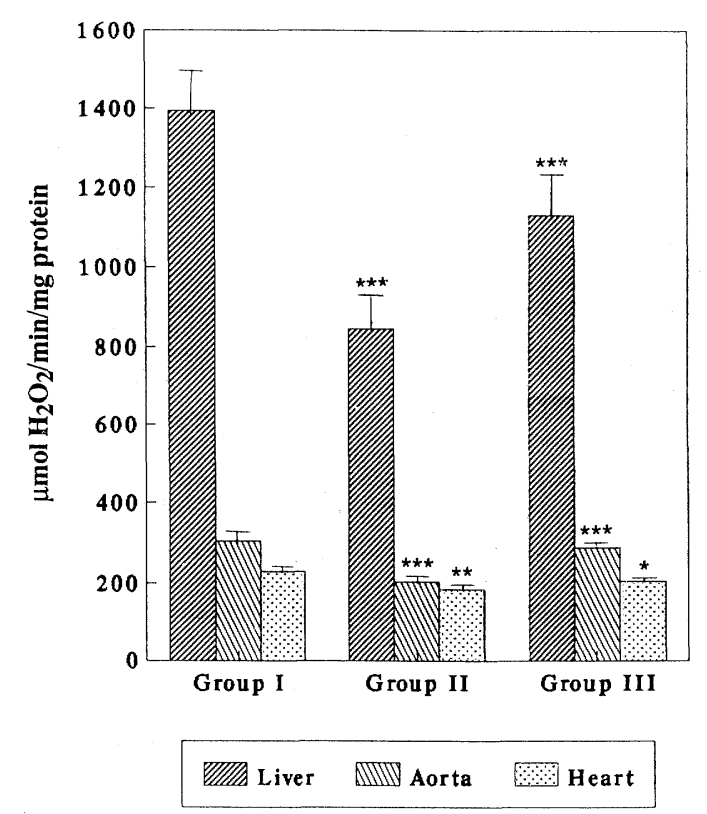

Fig. 2. Activity of catalase in liver, aorta, and heart of control and experimental animals. Values in $\mu \mathrm{mol} \mathrm{H}_{2} \mathrm{O}_{2}$ decomposed $/ \mathrm{min} / \mathrm{mg}$ protein are given as mean $\pm \mathrm{SD}$ for 6 animals in each group 2. Group II was compared with group I, and group III with group II $\left(* * * p<0.001,{ }^{* *} p<0.01,{ }^{*} p<0.05\right)$. 


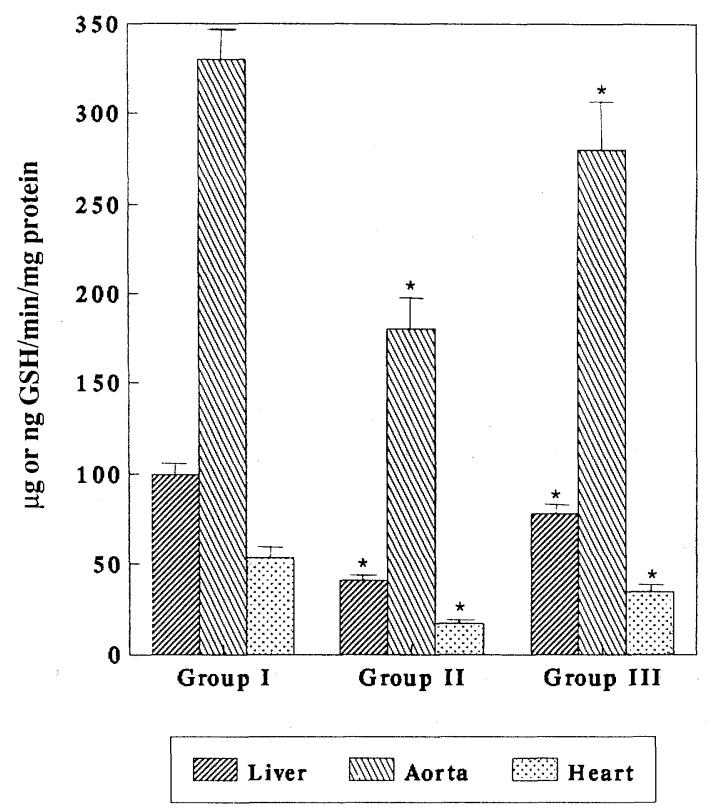

Fig. 3. Activity of glutathione peroxidase in liver, aorta, and heart of control and experimental animals. Values in $\mu \mathrm{g}$ or $\mathrm{ng}$ (for aorta) GSH utilized $/ \mathrm{min} / \mathrm{mg}$ protein are given as mean \pm SD for 6 animals in each group. Group II was compared with group I, and group III, with group II $\left({ }^{*} p<0.001\right)$.

methanol $(2: 1, \mathrm{v} / \mathrm{v})$, and the solvent was evaporated to dryness. The residue was used for the estimations of $\alpha$-tocopherol [16] and conjugated dienes (CD) [17]. $\mathrm{CD}$ concentration is also an index of lipid peroxidation.

LDL + VLDL was isolated as a single fraction from pooled human serum by precipitation with heparin, magnesium chloride, and sucrose [18]. The protein content of the isolated fraction was determined. The effect of TCR on in vitro oxidation of (LDL + VLDL) fraction was studied by the method described by Wallin et al. [19]. Briefly, $200 \mu \mathrm{g}$ (protein) of (LDL + VLDL) was suspended in $5 \mu \mathrm{M} \mathrm{CuSO}_{4}$ in phosphate-buffered saline. TCR (or rutin as a standard flavonoid) was added to the tubes in concentrations ranging from 0 to $125 \mu \mathrm{g}$ in terms of total flavonoids. Whole TCR contained $50 \%$ ethanol, and the amount of ethanol in the incubation mixture did not exceed 1\%. This concentration did not affect the reaction, as seen from the results obtained with the appropriate controls. Incubation was done at $37^{\circ} \mathrm{C}$ for $4 \mathrm{~h}$, and the lipid peroxides formed were estimated [10] and expressed in terms of nanomoles malondialdehyde (MDA) formed per $\mathrm{mg}$ (LDL + VLDL) protein.

Statistical analysis of the results obtained was done by Student's $t$-test. $p$ Values less than 0.05 were considered to be significant. Group I was compared with group II; and group II, with group III. 


\section{RESULTS}

Histopathological studies revealed that the aorta of group-I rats had a normal architecture (Plate 1). Several atherosclerotic changes like focal fat accumulation (Plate 2(a)), fibrin deposition (Plate 2(b)), and collagenization (Plate 2(c)), were seen in the aorta of group-II rats. The group-III rats, which were treated with the drug TCR, showed almost negligible changes, thus confirming the antiatherogenic effect of TCR (Plate 3).

A large increase $(p<0.001)$ in lipid peroxidation was observed in the serum and tissues of atherosclerotic rats (Tables 1 and 2). Group III (TCR administration) maintained lipid peroxidation at a significantly lower level when compared with group II $(p<0.001)$.

Depression in the level of GSH (Table 3) was observed in liver $(p<0.01)$, heart and aorta $(p<0.001)$ of group-II rats fed the atherogenic diet. Liver tissue showed a drastic depression $(p<0.001)$ in $\alpha$-tocopherol (Table 4) content, whereas in heart and aorta the depression was much less $(p<0.05)$. TCR could prevent the depression in the tissue GSH content of group-III rats $(p<0.001)$. The $\alpha$-tocopherol content was also maintained at normal levels in the heart and aorta, but not

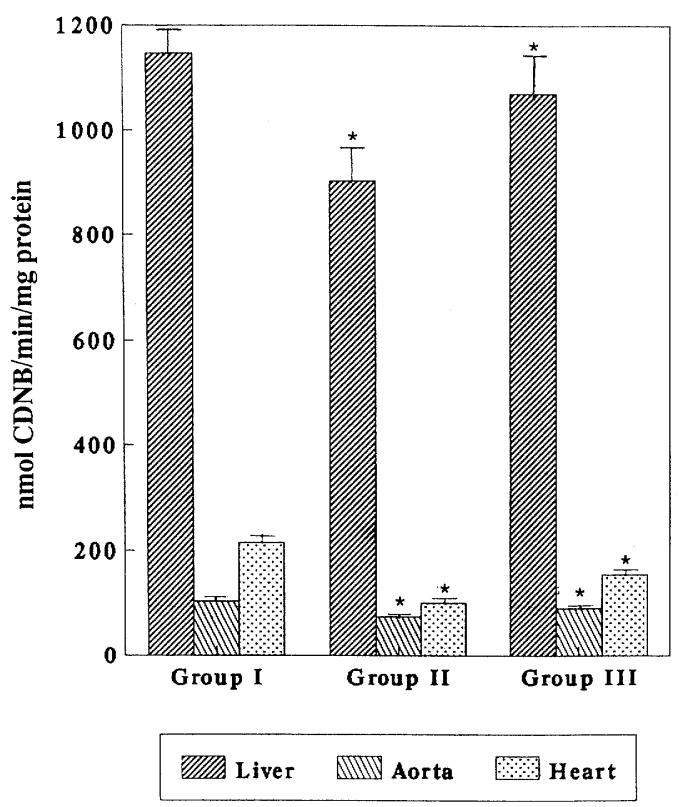

Fig. 4. Activity of glutathione-S-transferase in liver, aorta, and heart of control and experimental animals. Values in nmol CDNB conjugated $/ \mathrm{min} / \mathrm{mg}$ protein are given as mean \pm SD for 6 animals in each group. Group II was compared with group I, and group III, with group II $(* p<0.001)$. 


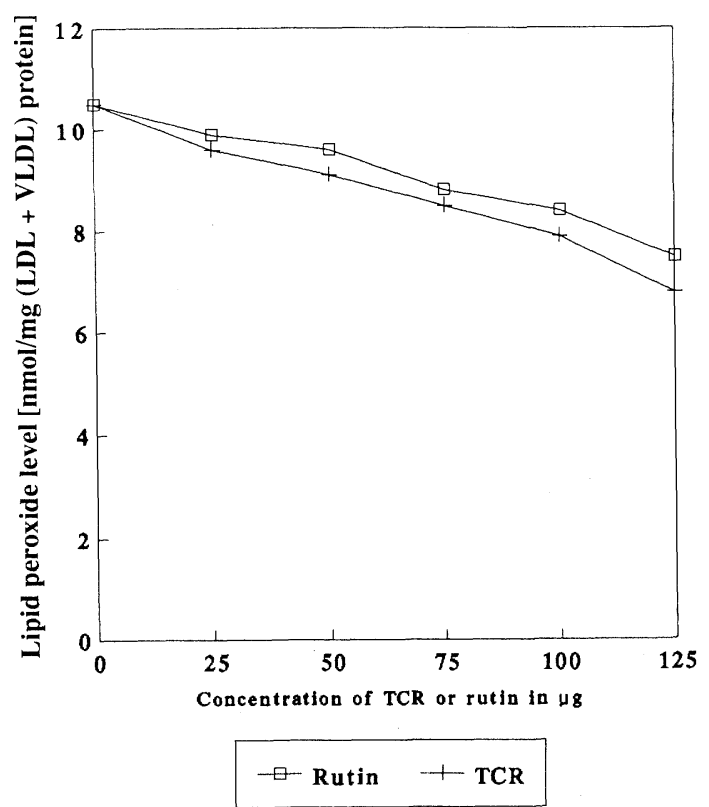

Fig. 5. Effect of tincture of Crataegus (TCR) or rutin on copper ion-induced oxidation of ( $\mathrm{LDL}+\mathrm{VLDL})$ in vitro. Concentration of TCR is given in terms of $\mu \mathrm{g}$ of total flavonoids present in it. Measurements in nmol MDA formed/mg (LDL + VLDL) protein are given as mean of triplicate analyses.

in the liver, of the TCR-treated group.

The activities of SOD, CAT, GPx, and GST were decreased significantly ( $p<$ 0.001 ) in the atherosclerotic group-II rats (Figs. 1, 2, 3, and 4). TCR treatment (group III) prevented the decrease in the activities of these enzymes significantly $(p<0.001)$ though the levels remained lower than those of the control animals.

The effect of TCR (and rutin) on the in vitro oxidation of (LDL + VLDL) is shown in Fig. 5. (LDL + VLDL) incubated in the absence of TCR (or rutin) showed a high concentration of lipid peroxides. A decrease in lipid peroxides was observed with increasing concentrations of TCR, showing that TCR inhibited the $\mathrm{Cu}^{2+}$ ion-induced oxidation of ( $\left.L D L+V L D L\right)$. We also observed that the percentage inhibition of oxidation by TCR was concentration dependent (Fig. 6) and that its effect was comparable to that of rutin, which was used as a standard.

\section{DISCUSSION}

Enhanced levels of lipid peroxides in serum and tissues have been demonstrated in atherosclerotic patients [20] as well as in animal models of atherosclerosis [21]. A similar condition was observed in this study, where an elevation in aortal lipid peroxides was also observed in the atherosclerotic animals. The lipid perox- 


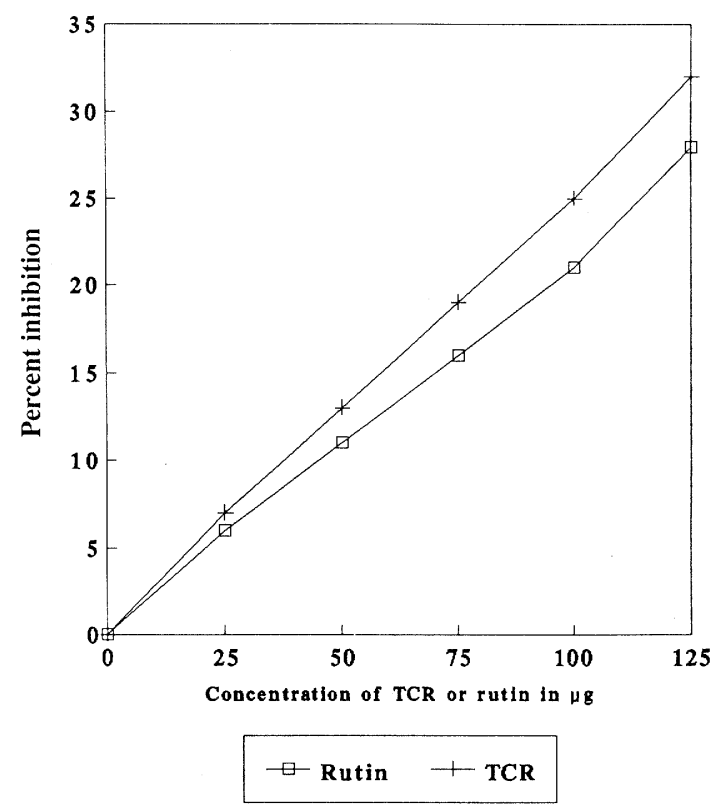

Fig. 6. Percent inhibition of oxidation of ( $L D L+V L D L)$ in vitro by TCR or rutin. Values were calculated based on $0 \%$ inhibition in the absence of either TCR or rutin.

ides may be a source of irritants to the arterial wall and may thus augment the atherogenic process [2]. TCR administration clearly inhibited lipid peroxidation in serum as well as in tissues in the group-III rats. The inhibition observed may have been due to the flavonoid as well as the saponin content of TCR. The flavonoids, rutin, and quercetin present in TCR have been shown to inhibit free radical processes in cells at various stages [22]. The triterpene saponins ursolic and oleanolic acid present in TCR may also contribute to the antioxidant effect of TCR, since these also have remarkable antioxidant activities [23]. It is likely that TCR protects the aorta from atherosclerotic changes by scavenging free radicals and thereby suppressing the peroxidation of lipids.

Reduced glutathione (GSH) protects the cell against free radicals and reactive oxygen intermediates. Exogenously administered GSH has been proved to ameliorate the oxidative stress due to atherosclerosis [24]. The decline in GSH content of liver, heart, and aorta observed in the present study could have been due to enhanced utilization of GSH for non-enzymatic oxidation by free radicals and reactive oxygen intermediates. TCR administration resulted in retention of almost normal levels of GSH in the tissues. TCR probably spared GSH from being utilized by removing the excessively generated free radicals.

$\alpha$-Tocopherol sequesters free radicals and acts as a chain-breaking antioxidant. A diminution of tissue $\alpha$-tocopherol in the atherosclerotic rats should have resulted in enhanced lipid peroxidation, thereby aiding the atherogenic process. 
TCR maintained the concentration of $\alpha$-tocopherol in aorta and heart at the control level in group-III rats, but in liver tissue the levels were lower than the control levels. Ascorbic acid is said to augment the antioxidant action of $\alpha$-tocopherol by reducing the $\alpha$-tocopheryl radical back to $\alpha$-tocopherol [25]. TCR probably assists the above process indirectly, since the flavonoids in it have an ascorbic acid-sparing property [26].

The activities of the enzymes SOD, CAT, GPx, and GST, which are the first line of defense against oxidative stress, were lowered due to the atherogenic diet in group-II animals. High amounts of lipid peroxides are significantly correlated with the decrease in the activities of the enzymes CAT [27], SOD [28], and GPx [29], which all of enzymes scavenge free radicals. Damage to the free radical-scavenging activities of the above enzymes may accelerate the atherogenic process. GST is an important enzyme that uses GSH as a substrate and detoxifies xenobiotics [2]. The decreased availability of GSH is probably the reason for decreased GST activity. TCR restored the activities of all these enzymes to almost normal levels in group III, and this effect is probably due to reversal of their inhibition by clearing the excess free radicals generated. GST activity was also maintained by TCR possibly by restoring the tissue GSH content to normal levels.

TCR was also found to inhibit the in vitro oxidation of (LDL + VLDL) induced by $\mathrm{Cu}^{2+}$ ions. Clearly this effect is largely due to its flavonoid content. Flavonoids can donate hydrogen or react with superoxide anions, hydroxyl radicals, and lipid peroxyl radicals, all of which can induce lipid peroxidation in vivo [30]. The flavonoids in TCR may act as scavengers of free radicals and other reactive oxygen species.

The results of the present study indicate that TCR prevents the increase in lipid peroxidation and corrects the imbalance in the antioxidant status produced due to atherosclerosis in a rat model. It also prevents the in vitro oxidation of the atherogenic lipoproteins LDL and VLDL, which suggests that a similar mechanism may be involved during its antiatherogenic activity in vivo.

Shanthi Rajendran, Parasakthy, K., and Deepalakshmi, P.D. are grateful to the University Grants Commission and Council of Scientific and Industrial Research, New Delhi, India, for research assistantships.

\section{REFERENCES}

1. Steinberg, D., Parthasarathy, S., Carew, T.E., Khoo, J.C., and Witztum, J.L. (1989): Beyond cholesterol. Modifications of low density lipoprotein that increase its atherogenicity. $N$. Engl. J. Med., 320, 915-924.

2. Halliwell, B., and Gutteridge, J.M.C. (1989): Free radicals, ageing and disease, in Free Radicals in Biology and Medicine, ed. by Halliwell, B., and Gutteridge, J.M.C., Clarendon Press, Oxford, pp. 421-422.

3. Esterbauer, H., Wag, G., and Puhl, H. (1993): Lipid peroxidation and its role in atherosclerosis. Br. Med. Bull., 49, 566-576.

4. Shanthi, S., Parasakthy, K., Deepalakshmi, P.D., and Devaraj, S.N. (1994): Hypolipidemic

Vol. 20, No. 3, 1996 
activity of tincture of Crataegus in rats. Indian J. Biochem. Biophys., 31, 143-146.

5. Wickham, C. (1981): Crataegus oxyacantha, in Common Plants as Natural Remedies, ed. by Wickham, C., Frederic Muller Ltd., London, pp. 48-49.

6. Boericke, W. (1927): Crataegus, in Pocket Manual of Homoeopathic Materia and Medica, Boericke and Runyon, Philadelphia, pp. 237-238.

7. Toote, J., and Vlietinck, A.J. (1986): Phytotherapy and cardiovascular system. J. Pharm. Belg., 41, 330-361.

8. Beretz, A., and Cazenave, J.P. (1988): The effect of flavonoids on blood-vessel wall interactions, in Plant Flavonoids in Biology and Medicine II, Biochemical, Cellular and Medicinal Properties, Alan. R. Liss, Inc., New York, pp. 187-200.

9. Bajwa, G.S., Morrison, L.M., and Ershoff, B.H. (1971): Induction of aortic and coronary athero-arteriosclerosis in rats fed a hypervitaminosis D, cholesterol containing diet. Proc. Soc. Exp. Biol. Med., 138, 975-982.

10. Ohkawa, H., Ohishi, N., and Yagi, K. (1979): Assay for lipid peroxides in animal tissues by thiobarbituric acid reaction. Anal. Biochem., 95, 351-358.

11. Moron, M.S., Defierre, J.W., and Mannervik, K.B. (1979): Levels of glutathione, glutathione reductase and glutathione-S-transferase activities in rat lung and liver. Biochim. Biophys. Acta, 582, 67-78.

12. Misra, H.P., and Fridovich, I. (1972): The role of superoxide anion in the auto-oxidation of epinephrine and a sample assay for SOD. J. Biol. Chem., 247, 3170-3175.

13. Bergmeyer, H.U., Gawehni, K., and Grassl, M. (1974): Enzymes as biochemical reagents, in Methods of Enzymatic Analysis, Vol. 1, ed. by Bergmeyer, H.U., Academic Press, New York, pp. 438-439.

14. Rotruck, J.T., Pope, A.L., and Ganther, H.E. (1973): Selenium, biochemical role as a component of glutathione peroxidase-purification and assay. Science, 179, 588-590.

15. Habig, W.H., Pabst, U.J., and Jakoby, W.B. (1974): Glutathione-S-transferase. J. Biol. Chem., 249, 7130-7139.

16. Desai, I.D. (1984): Vitamin E analysis methods for animal tissues, in Methods in Enzymology, Vol. 105, ed. by Packer, L., Academic Press, New York, pp. 138-147.

17. Recknagel, R.O., and Glende, E.A., Jr. (1984): Spectrophotometric detection of lipid conjugated dienes, in Methods in Enzymology, Vol. 105, ed. by Packer, L., Academic Press, New York, pp. 331-337.

18. Burstein, M., and Scholnick, H.R. (1973): Lipoprotein-polyanion metal interactions. $A d v$. Lipid Res., 11, 68-108.

19. Wallin, B., Rosengren, B., Shetzer, H.G., and Camejo, G. (1993): Lipoprotein oxidation and measurement of thiobarbituric acid reactive substance formation in a single microtiter plate: Its use for evaluation of antioxidants. Anal. Biochem., 208, 10-15.

20. Stringer, M.D., Gorog, P.G., Freeman, A., and Kakkar, V.V. (1989): Lipid peroxides and atherosclerosis. Br. J. Med., 298, 281-284.

21. Goto, Y. (1982): Lipid peroxides as a cause of vascular disease, in Lipid Peroxides in Biology and Medicine, ed. by Yagi, K., Academic Press, San Francisco, pp. 295-303.

22. Afanasev, I.B., Dorozhko, A.I., Brodskii, A.V., Kostyuk, V.A., and Potapovitch, A.I. (1988): Chelating and free radical scavenging mechanisms of inhibitory actions of rutin and quercetin in lipid peroxidation. Biochem. Pharmacol., 138, 1763-1769.

23. Balanehru, S., and Nagarajan, B. (1991): Protective effect of oleanolic acid and ursolic acid against lipid peroxidation. Biochem. Int., 24, 981-990.

24. Ol'Shanskii, G.S., and Khanin, A.L. (1975): Oksidoredktsiya, Aterogoenez Ischemicheskaya Bolezn Serdtsa, ed. by Ol'Shanskii, G.S., U.S.S.R., $47 \mathrm{pp}$.

25. Leung, H.W., Vang, M.J., and Mavis, R.D. (1981): The cooperative interaction between vitamin $\mathrm{E}$ and vitamin $\mathrm{C}$ in suppression of peroxidation of membrane phospholipids. Biochim. Biophys. Acta, 664, 266-272.

26. Middleton, E., Jr. (1984): The flavonoids. Trends Pharmacol. Sci., 5, 334-338.

27. Remacle, J., Lambert, D., Raes, M., Pigeolet, E., Michiels, C., and Toussaint, O. (1992): 
Importance of various antioxidant enzymes for cell stability. Biochem. $J$., 286, 41-46.

28. Wang, J., Lu, Y.C., Zhen, E.Z., Guo, Z.Z., and Liu, X.Q. (1987): Lipid peroxide metabolism and PGI2/TXA2 balance in hyperlipidemic rabbits: Study of the anti-atherosclerosis effects of Rhapoticum uniflorum DC, Natl. Med. J. China, 67, 276-283.

29. Lankin, V.Z., Vinkhert, A.M., Kosykh, V.A., Tikhaze, A.K., Galakhov, I.E., Orekhov, A.N., and Repin, V.N. (1984): Enzymic detoxication of superoxide anion radicals and lipoperoxides in intima and media of atherosclerotic aorta. Biomed. Biochim. Acta, 43, 797802 .

30. Frankel, E.N., Kanner, J., German, J.B., Parks, E., and Kinsella, J.E. (1993): Inhibition of oxidation of human low density lipoprotein by phenolic substances in red wine. Lancet, 341, 454-457. 